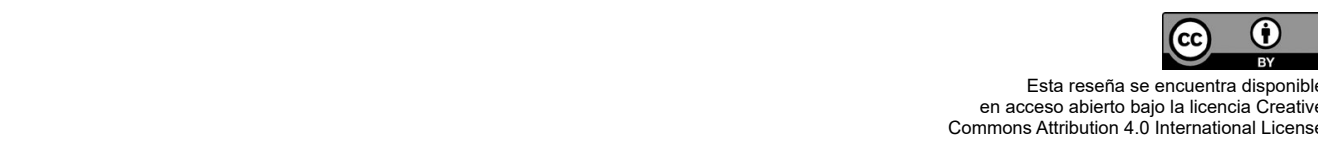

Revista Oficial del Poder Judicial

ÓRGANO DE INVESTIGACIÓN DE LA CORTE SUPREMA DE JUSTICIA DE LA REPÚBLICA DEL PERÚ

Vol. 13, n. 16 , julio-diciembre, 2021, 511-516

ISSN: 1997-6682 (Impreso)

ISSN: 2663-9130 (En línea)

DOI: 10.35292/ropj.u13i16.468

\title{
Carlos Calderón Puertas. \\ Introducción al Derecho. Una mirada desde la literatura y otras artes.
}

Lima: LP Editorial, 2021, 352 pp.

0

Cuando se habla de textos introductorios, en cualquier disciplina, por lo general pensamos en libros con herramientas fáciles de aprender, resúmenes o conceptos bastante concisos que, como si fueran recetas, deben aplicarse pragmáticamente en casos específicos. El derecho no es ajeno a este tipo de textos. En general se piensa en el estudio de esta disciplina como un canon definido por lo jurídico y, en menor medida, por su relación con otras disciplinas. Sin embargo, existen otras formas de abordar el ingreso al derecho, como es el caso de Introducción al Derecho. Una mirada desde la literatura y otras artes, libro de Carlos Calderón Puertas, publicado en Lima por LP Editorial, que consta de 352 páginas y cuya primera edición vio la luz en septiembre de 2021. En este ejemplar, de manera interdisciplinaria, se ha logrado una suerte de visión humana sobre los aspectos legales y, en cada uno de los capítulos, el autor ha redescubierto un problema social, filosófico o antropológico. De esta manera, a la luz de las normas, 


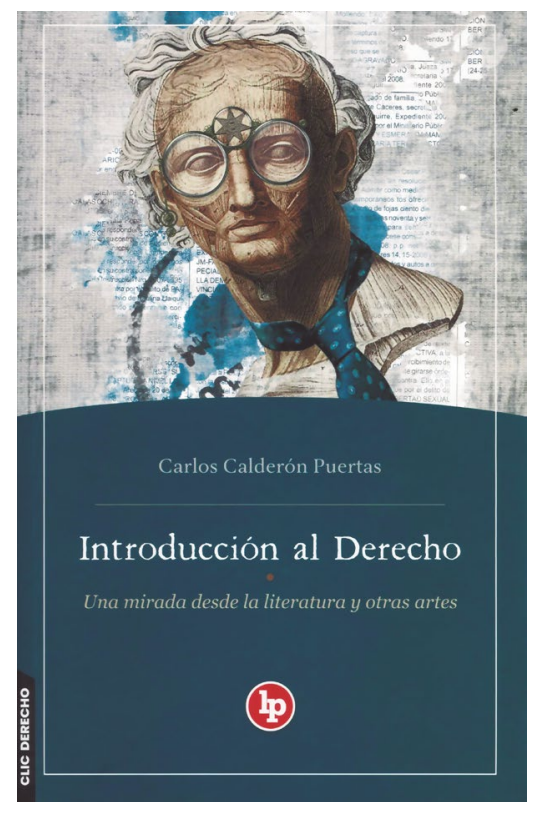

reflexiona y conecta entre ellos. La gran línea que atraviesa todos los capítulos busca redescubrir el sentido de la justicia en los conflictos humanos, incluso en los más cotidianos. En este texto de Calderón Puertas se invita al lector a introducirse en el derecho desde el análisis del texto literario, aunque también desde aspectos biográficos de personajes o el cine. En cualquier caso, la potencia de las historias (ya sean ficcionales o no) conserva dentro de sí una carga de sentido que será trabajada desde lo jurídico y extrapolada a la reflexión filosófica.

Nos topamos, por ejemplo, con temas como el asesinato en «La triste muerte de Edwin Elmore», donde el autor recoge los acontecimientos del conflicto entre Edwin Elmore y José Santos Chocano, con la consecuente muerte del primero. Asimismo, dentro del análisis del caso, se explican cuáles fueron los alegatos de cada parte, las ofensas mutuas, las misivas y, además, se representa la influencia que tuvo (en su momento) la literatura sobre la política y el mundo legal. Por otra parte, así como el texto aborda la muerte de Elmore, también trabaja el análisis del juicio a César Vallejo. Para tal fin, se ha logrado señalar, de manera panorámica, los elementos polémicos del proceso legal y, además, el autor detalla el estadio de Vallejo en prisión, donde el poeta produjo textos de suma importancia para el canon literario nacional e internacional.

El libro de Calderón Puertas no es solamente un conjunto de relatos biográficos analizados en clave jurídica; por el contrario, estamos frente a un texto que, desde lo interdisciplinario, le otorga 
al lector la oportunidad de conocer el derecho desde la literatura, o, dicho de otra forma, desde la vida misma. En tal sentido, se tocan temas profundamente filosóficos que le atañen a la vida humana: la dignidad en la muerte, la pregunta por el sentido de la vida, la polémica por el surgimiento de la vida y las limitaciones del ser humano. De esa forma, en «Mo cuishle. La dignidad de la muerte humana» se discute si uno posee el derecho a decidir sobre el final de su propia vida (ya que no tuvo elección en el nacimiento). Se exponen las diversas posturas al respecto, desde lo teológico hasta los conceptos estrictamente médicos. De aquí se trae a colación la película Million Dollar Baby para tratar un tema de fondo bastante complejo: la eutanasia. Asimismo, en «Un mundo feliz. La naturaleza jurídica de los embriones humanos» observamos el debate, que ya tiene varios años vigente, sobre el inicio de la vida del ser humano. Sin embargo, el texto también plantea la responsabilidad que tienen las autoridades para decidir sobre los embriones, la capacidad del Estado para legislar sobre ellos y, en un escenario distópico, representar las posibilidades malintencionadas del ser humano para su control. En ese sentido, Introducción al Derecho. Una mirada desde la literatura y otras artes se sirve del discurso literario para catapultar una serie de reflexiones sobre la vida humana, que alcanzan varios estratos de ella, y que ejemplifican los conflictos morales en los que se ve sumergido el hombre.

De otro lado, el libro del doctor Calderón Puertas también invita al cuestionamiento sobre la crisis que vive nuestro sistema judicial. De la misma manera, propicia la reflexión sobre el papel de los jueces y su dimensión humana mientras realiza un mapeo por el período del gobierno de Alberto Fujimori. Por esta razón, se explica, además, que la crisis generalizada del Poder Judicial no es un caso aislado, sino que está presente en casi toda América Latina. Antes bien, el autor provee de cifras que reflejan el descrédito institucional de los últimos años del Poder Judicial a ojos de la población 
peruana. En ese sentido, resulta pertinente enmarcar que todo esto se da en el contexto de los cambios de constitución que ha experimentado el país. Por lo tanto, se podría decir que el texto transita sobre diversos aspectos ligados al derecho de manera directa, desde la reflexión legal-filosófica hasta el contexto histórico que engloba los cambios constitucionales. Asimismo, observamos un vaso comunicante presente en todos los capítulos: la pregunta por el lugar de la justicia.

Entonces, además de la crítica al sistema de justicia, el texto desarolla un análisis de quienes imparten justicia y cómo realizan sus labores en distintos espacios geográficos. Por esta razón, a partir de la novela de Ciro Alegría, El mundo es ancho y ajeno (1941), se plantea la crítica a los magistrados que, en algunos casos, han pasado el límite de lo legal y lo moral para servirse a sí mismos. De manera que el texto de Alegría relata de forma verosímil el accionar de jueces con el consecuente daño a la población, así como también se menciona en otros de sus cuentos. De cualquier modo, Calderón Puertas va más allá de los casos de corrupción o nepotismo. El autor extiende el análisis a la figura actual del juez y cómo es percibido por la sociedad. A propósito de esto, también identifica uno de los principales problemas del sistema judicial: no son solo los trabajadores del mismo Poder Judicial, sino aquellos que a pesar de ser externos utilizan los lazos amicales establecidos durante la vida universitaria para hacerse de favores. En cualquier caso, la visión que tiene la población de las instituciones que imparten justicia y también de sus jueces o fiscales es la misma: no hay justicia, y si la hay entonces es muy cara. Por este motivo, el texto se repregunta constantemente por el espacio de la justicia en el país y, de alguna forma, advierte a quienes están insertándose en el mundo legal para evitar que estos casos sigan replicándose. 
Por donde se le mire, a este texto introductorio le son propios los análisis de los escenarios legales de los conflictos, las crisis de las instituciones, la crítica a los procesos judiciales de los últimos años, la muerte digna, entre otros. No obstante, así como la búsqueda de la justicia es el vaso comunicante en todo el texto, existe otro pilar dentro de los apartados del libro de Calderón Puertas: la condición humana. Así se observa en el capítulo titulado "Los monstruos. La ley y los otros», donde se configura al monstruo, en primera instancia, a nivel físico, como se ha realizado de manera tradicional: alguien que está en los límites del ser y que causa una mezcla de emociones negativas, que van desde el asco hasta el odio. Posteriormente, se da paso a una reconfiguración del monstruo desde su fuero interno, donde ya no se habla de él por su aspecto físico, sino por su personalidad y sus intenciones. En consecuencia, el autor se pregunta por el lugar del monstruo y cómo, desde nuestra individualidad, le hemos atribuido una retahíla de características que, en muchos casos, son una proyección de nosotros sobre ellos. Luego, redefine al monstruo moderno, no como antaño, cuando se hablaba del ser deforme o grotesco, sino más bien como una degradación del sujeto, que está excluido de la sociedad y a quien no le es permitido tratar de reinsertarse: son los otros.

Finalmente, Introducción al Derecho. Una mirada desde la literatura y otras artes es un caso sui generis. Por un lado, le permite al lector introducirse en el mundo del derecho desde discursos heterogéneos, por lo que constituye una manera novedosa de analizar las historias en clave jurídica. Por otro lado, el libro propone una humanización de los casos a ojos de los trabajadores del ámbito legal. No estamos hablando solo de entender los conflictos en sus distintas dimensiones, sino que existe una preocupación real del autor de trabajar el tema de la vida humana. En pocas palabras, en este libro el lector encontrará, sin duda, un ánimo vallejiano que recoge problemas universales como el dolor, la paternidad, el 
amor, la muerte, los otros, todo ello para desentrañar que el derecho no está solamente en el sistema de justicia, sino que se encuentra en lo cotidiano. Está presente en los sucesos más insignificantes de la vida, solo hay que mirarlo de otra forma.

Gustavo Reynaldo Dominguez Chincha

Universidad Antonio Ruiz de Montoya (Lima, Perú)

Contacto: a2110022@uarm.pe https://orcid.org/0000-0003-1488-3484 